\title{
Defining diversity in groupwork: \\ A relational exploration
}

\section{Melissa Popiel ${ }^{1}$, Sarah LaRoque ${ }^{2}$, David Nicholas ${ }^{2}$, Christopher Kilmer ${ }^{2}$, David Este ${ }^{2}$, and William Pelech ${ }^{2}$}

\begin{abstract}
Underlying traditional definitions of diversity is a focus on individual or social group characteristics, which is problematic to groupwork. Toward remediating this issue, this paper explores groupworker understandings of diversity and how perceptions impact approaches to diversity arising in groups. The overall project consists of sequential phases reflective of a mixed-methods design, beginning with interviews and focus groups at locations across Canada. Grounded theory methods guided the analysis. In the study, groupworkers reported feeling overwhelmed and, in some cases, 'paralyzed' by the complex diversity in groups. In keeping with the traditional aims of groupwork, attending to diversity goes beyond the group to include responses to diversity in organizational and community contexts. A critical step in moving forward is to examine the nuances of diversity and move beyond thinking of diversity merely in terms of demographic variables to include relational and intersectional identities of group members.
\end{abstract}

Keywords: diversity; relationality; intersectionality; grounded theory; mixed methods; groupwork; direct practice; macro practice; group work

1. Wilfrid Laurier University, Canada

2. University of Calgary, Canada

Address for correspondence: mpopiel@wlu.ca

Date of first (online) publication: 3rd December 2021

Funding: The study was funded by the Social Sciences and Humanities Research Council (SSHRC), one of Canada's major funders for university researchers. We received funding from one of the core programs under SSHRC known as the 'Insight Grant.' The grant was for five years with the possibility of extensions. 


\section{Introduction}

Researchers and groupworkers have noted the positive potential of differences that group members bring (Balgopal and Vassil, 1983; Coyle, 1930; Goroff, 1980; Kaiser, 1958; Newstetter, Feldstein and Newcomb, 1938; Phillips, 1957; Shulman, 2006; Sullivan, 2004; Tropp, 1969; Van Veelen, Otten and Hansen, 2013). Such differences include the potential for bolstered problem-solving strategies (McLeod, Lobel and Cox, 1996) and exposure to coping strategies (Balgopal and Vassil, 1983; Flores, 2017). Yet despite the potential, diversity in groups results in a range of outcomes, including greater creativity, improved solutions, and more conflict (Fernandes and Polzer, 2015; Jordaan and Jordaan, 2019; Pelled, Eisenhardt and Xin, 1998; Van Veelen, Otten and Hansen, 2013).

Complicating the understanding of the impact of diversity on cohesion, Toseland and Rivas (2012, p.62) suggest that 'similar demographic backgrounds of members' are related to group cohesion, which is, in turn, a predictor of positive outcomes in groups. Studies on group diversity have identified concerns related to group integration, cohesion, commitment, and communication when demographically diverse participants are present (Ancona and Caldwell, 1992; Chatman and Flynn, 2001; Galinsky et al, 2015; Harrison, Price and Bell, 1998; O'Reilly, Caldwell and Barnett, 1989; Shaw and Barrett-Power, 1998; Zenger and Lawrence, 1989). A lack of effective strategies may contribute to attrition rates in treatment groups with diverse members. In a metaanalysis of 125 studies, Wierzbicki and Pekarik (1993) reported a mean dropout rate of $46.9 \%$.

Additionally, groupworkers have expressed concerns about how group members perceive the worker's understanding of cultural issues, resulting in reduced member participation in discussions (Camacho, 2002). Most disturbingly, when facing group member differences or working with members from different backgrounds, is a lack of response to the differences (Rittner, Nakanishi, Nackerud and Hammons, 1999). These negative associations stress the importance of the skillset and confidence of groupworkers to proactively and constructively manage and support the diversity inherent in treatment and task groups. A critical step in moving forward is to examine the nuances of diversity and move beyond thinking of diversity in terms of demographic variables. 


\section{Literature review}

In the literature, diversity is understood in multiple ways. Typically, diversity is described as a demographic criterion with multiple dimensions, such as gender, race, ethnicity, age, religion, social class, sexual orientation, and geographical background (Hiranandani, 2012; Hitt, Miller and Colella, 2015). In a recent article, Inegbedion, Sunday and Asaleye (2020) defined diversity as:

it [diversity] refers to the differences ... as a result of the various backgrounds to which they belong. These backgrounds include but are not limited to gender, age, race, color, ethnicity and physical ability. (p.2)

Along similar lines, Weber, Sadri and Gentry (2018, p.383) described the term as 'social identity characteristics such as demographic variables (i.e., age, gender, race, and ethnicity), values, beliefs or cultural backgrounds.' Diversity can also be viewed as, 'any attributes that people use to tell themselves that another person is different' (p.903).

In social work, while 'diversity' and 'difference' are often used interchangeably, diversity is defined in a narrow sense, reduced to characteristics 'possessed' by individual members. If one narrowly defines diversity, members sharing similar characteristics may seem to have the same beliefs, values, and experiences (Azzopardi, 2020; Azzopardi and McNeill, 2016), which may not be the case. It is then, in operational terms, that the concepts of diversity and difference coincide. A narrow understanding of diversity fails to acknowledge that although outward characteristics of individual members may appear relevant, so are the different perspectives or worldviews brought to the group (Varghese, 2016). Group members of diverse backgrounds may have ideas, beliefs, or values consistent with or different from group members from a perceived similar background.

Anderson (1997) and Sullivan (2004) note that while every human being is unique, each person is like others in cultural and group influences and sharing basic human needs. Van Knippenberg and Schippers (2007, p.516) define diversity as 'a characteristic of social grouping that reflects the degree to which objective or subjective differences exist between group members.' Doyle and George (2008) emphasize the significance of social group-based characteristics as

the most relevant forms of diversity... are group-based characteristics, on 
the basis of which many, but not necessarily all, group members have been and/or are subject to marginalization and/or oppression. (p.16)

When the assumption that diversity is a characteristic possessed by an 'other' perceived to be different and inferior becomes a guiding principle in groupwork, marginalization of members can result. Marginalization can be a negative response to essentialized definitions of diversity arising from comparisons with a dominant majority. This association between diversity and inferiority has been a tragic part of human existence, given voice in Social Darwinism and the Eugenics Movement of the early 20th century (Claeys, 2000). Perceived inferior characteristics were viewed as a threat to human progress and were thus subject to overt suppression. While western societies have made some progress since that time for specific groups, there remain similar discrimination patterns against those perceived as different. Moreover, traditional definitions imply that diversity is present when group members differ in some way from the characteristics or views generally ascribed to by members of dominant societal groups (Van Knippenberg and Schippers, 2007).

Additionally, historical means of labeling or describing culture, race, ethnicity, gender, sexual orientation, ability, status, or social class reflects a social structure of privilege and oppression (Marsiglia, Kulis and Lechuga-Peña, 2021). As Miller, Donner and Fraser (2004, p.377) state, 'differences in social identity not only involve difference but also represent social inequities of power, privilege and oppression.' Diversity is often associated with imbalances of power and privilege, which arise from broader social environments in which members of particular identity groups are perceived as normative and provided with certain rights and advantages - for example, male privilege, White privilege, or heterosexual privilege (Roysircar, 2008; Smith and Shin, 2008).

Diversity is also associated with issues of oppression related to experiences of deprivation, exclusion, discrimination, and marginalization based on social identity (Burnes and Ross, 2010; Phillips, Slepian and Hughes, 2018). Just as diverse groups reflect the social world, they also reflect normative social power relationships and societal forms of oppression (Alvarez and Cabbil, 2002; Bemak and Chung, 2004; Greene, 2004; Marbley, 2004; Saino, 2003; Shapiro, 1990). Green and Stiers (2002, p.233) refer to 'the unacknowledged and unspoken imbalance of power' that often exists in multicultural 
group therapy contexts. According to Brown and Mistry (2006, p.133), "patterns of social oppression will be repeated in groupwork unless active steps counteract these tendencies and replace them with a culture of empowerment.' For this reason, it is an ethical imperative that groupworkers avoid the dangers of overgeneralizing or stereotyping, which can be done by being sensitive to the uniqueness of each member (Ganzer and Ornstein, 2002; Northen, 1988).

\section{Background to the study}

\section{Impetus}

Today, there is an increasing awareness of the changing demographics in our communities and the need for culturally sensitive practice. Just as societal responses have not always affirmed diversity, the expression of diversity in groups may result in beneficial or harmful responses. Regrettably, delaying acceptance of diversity may be associated with significantly higher dropout rates among diverse populations (Apfelbaum, Stephens and Reagans, 2016). However, limited research addresses the role diversity plays in groupwork and how groupworkers may effectively engage clients with a wide range of diversities in group. The current state of knowledge regarding groupwork and diversity indicates that when faced with differences, groupworkers often do nothing to address these issues directly (Boler, 2017).

\section{Audience}

The intended primary beneficiaries of the study are groupworkers who engage with diverse members in their practice. More specifically, we hope groupworkers will be more comfortable and effective in preparing for and responding to issues of diversity in the group context.

\section{Groupwork experience of authors}

There is a range of experience that the authors possess in relation to groupwork. Dr. Sarah LaRocque has been involved with research, education, and practice since 1990. Her practice experiences 
include a range of psycho-education, treatment, and long-term psychotherapy groups for persons with complex trauma, personality disorders, interpersonal concerns, and health issues. She provides interdisciplinary group training in both psycho-education and longterm psychotherapy groups. Dr. William Pelech possesses over 25 years of experience with research, education, and practice with groups. His practice experience includes trauma, addictions, intimate partner violence, male sexual abuse survivors, and groups addressing various clinical orders (Axis I). Dr. Pelech is co-author of the book entitled 'Inclusive Group Work.' Dr. David Nicholas has been involved with research, education, and practice with groups. Since 2000, his research focus includes education of online groups and groupwork with individuals with health and disabilities. Throughout his career, Dr. David Este has engaged in groupwork with individuals with severe mental illness and persons who have experienced head injury trauma. Dr. Melissa Popiel brings her experience as a researcher and educator in diversity and social justice to the team. Her work has utilized a structural systems perspective integrating perspectives at micro, mezzo, and macro levels of social work practice. Finally, Mr. Chris Kilmer was involved in groupwork during one of his BSW practicums.

\section{Study objectives}

Toward this aim of counteracting patterns of oppression, the overall objectives of this study are to:

- Understand groupworkers' experiences and perceptions of diversity in treatment groups;

- Develop strategies that enable groupworkers to more effectively respond to diversity in their groups;

- Organize these strategies into a practice model; and,

- Examine the benefits of this diversity-informed practice model with comparable groups.

This paper explores the first and second phases of the data collected, focusing on groupworkers' existing understandings of diversity and how perceptions impact approaches to diversity arising in group, with implications for group practice advancement. 


\section{Methods}

The project consists of sequential phases following a mixed-methods design. In the initial phase (phase one and the focus of this manuscript), in-depth semi-structured qualitative interviews were conducted individually with groupworkers to understand their experiences with the emergence of diversity throughout the various phases of groups. The second phase consisted of focus groups with groupworkers, wherein findings from the previous phase were reviewed and built upon to generate a model of working with diverse clients. The third (and current) phase of the study is testing the newly developed model of working with diversity in group environments. Following testing, a fourth phase will explore groupworkers' experiences of working with the model, and the model will be further refined. The following sections will focus on worker understandings of diversity in groupwork practice.

\section{Sampling}

In this study, we used theoretical and criterion sampling strategies. Theoretical sampling includes jointly collecting and analyzing data to decide what data to collect next to develop theory (Glaser and Strauss, 1967). According to Patton (2002), criterion sampling includes selecting cases that meet some predetermined criterion of importance. The criteria utilized to select participants were:

- Groupworkers who possess a minimum of three years of groupwork experience;

- A graduate degree in human services or specialization in psychiatry;

- Affiliation with a hospital, social service agency, or groupwork association;

- Currently leading a support group for adults; and

- Practising groupwork in Calgary or Edmonton, Alberta, or Southern Ontario, Canada

\section{Recruitment}

Members of the research team conducted the recruitment. Two primary 
recruitment strategies engaged individuals to participate in the study. A poster describing the project was created by the team and circulated to local groupwork practice agencies. Participants interviewed were also invited to refer groupworker colleagues to the study.

\section{Data Collection}

The data collection methods involved were semi-structured interviews and focus groups. Members of the research team completed 24 interviews and 6 focus groups. Ayres (2008, p.811) noted, 'it is a qualitative data collection strategy in which the researcher asks informants a series of predetermined open-ended questions.' There is a strong consensus within the literature that the semi-structured interview format provides the interviewer with the flexibility to gain an enhanced understanding of the experiences of interviewees (Low, 2013; McIntosh and Morse, 2015; Newcomer, Feldstein and Newcomb, 2015). The focus groups allowed for follow-up questions related to the experience of power in group and techniques used to support diversity arising in group.

Two research team members developed the initial interview guide. Once the initial draft was completed, it was reviewed by the team until a consensus was reached. Following the first interviews, changes were made to the guide to reflect changes in themes discussed by participants (Thomas, 2006).

The following are examples of the interview and focus group questions posed to the study's respondents: 1) How do you understand diversity as it occurs in your group practice?; 2) Based upon your understanding, please describe the ways that diversity arises in your groups.; and 3) Recalling your previous groupwork experiences, describe an example where you encountered diversity in one of your groups. Probes to expand on the last question included: a) At what stage in the group did this occur (encountering diversity)?; b) How did you and/or your coworker respond?; c) How did the group members respond?; and d) How did these responses impact the groups?

The interviews ranged from 45 to 90 minutes, conducted at sites agreed upon by the research participant and interviewer. The focus groups were between 90 to 120 minutes in length. Data gathering 
sessions were audio-recorded and transcribed verbatim for the analysis that followed. We utilized ATLAS.ti version 7 to assist with both data management and analysis.

The host university completed an ethics review and approval; informed consent was received prior to study participation.

\section{Data analysis}

The analysis was guided by Glaser and Strauss's (1967) Grounded Theory-based constant comparative method with subsequent methodological guidance by Corbin and Strauss (2014). Initial opencoding entailed a line-by-line review of the data, resulting in discrete units of meaning, followed by axial coding, wherein data were categorized, and connections developed between concepts. Finally, selective coding entailed forming core categories and reflecting upon, refining, and developing emergent relationships.

\section{Rigor}

Rigor was achieved through multiple means, including data saturation, inter-rater reliability via multiple independent coders, team reflection to reach consensus, and triangulation via multiple data collection sites (Lincoln and Guba, 1985; Padgett, 2008; Tuckett, 2005). Multiple illustrative participant quotes provide referential adequacy, as shown in this article.

\section{Results}

\section{Profile of study participants}

Participants were drawn from two large cities in western Canada and various locations within one central Canadian province, providing significant regional diversity. A total of 24 groupworkers participated in interviews. Participants self-identified socially diverse categories, including 19 females, 4 males, and 1 transgender person. Cultural origins represented included South Asian; Northern, Eastern, and Western European; Middle Eastern; and Latino. Among the 
professional backgrounds were social work, occupational therapy, counseling in education, psychology, art therapy and sociology. Group topics represented in the sample included support, mental health psycho-education, intimate partner violence, disability, personal development, addictions, forensic groups, and social skill development. The duration of groups ranged from four weeks to one year. Variation was also present in the group format (open, closed, drop-in) host agency, and location.

Focus groups were conducted at two sites but included participants from different geographic locations in Alberta and Ontario. In total, 20 participants were involved. In Calgary and Edmonton, Alberta, two groups were conducted face-to-face. Two groups were remotely conducted in Southern Ontario using video conferencing software. The focus groups occurred in two rounds; in round one, one focus group was conducted in each area, with the process was repeated in the second round, with three more focus groups.

\section{Groupworker understanding of diversity}

When asked how they understood diversity, the groupworkers initially described demographic and group composition variables, including age, gender, sexual orientation/identity, ethnicity, religion, language, socio-economic factors, disabilities, and member characteristics based on inclusion criteria. The responses below are examples of this understanding of diversity.

Within my practice, when I think of the word diversity, I think of culture, religion, people from different backgrounds, and languages. (P23)

I think that diversity happens all the time in group. Sometimes it's a little more obvious in terms of demographic - different genders, different ages, different ethnic and cultural backgrounds, or different problems they bring into group. (P10)

Interestingly, as participants reflected on how diversity emerges in groups, perceptions evolved into more complex understandings, including an interplay of member diversity, group relational processes, organizational policies, social context, and groupworker confidence 
responding to diversity. 'In terms of other diversity, there's definitely learning disabilities, mental health, and physical disability.' (P15)

\section{Member diversity}

As participants further considered diversity, definitions expanded to include lived experiences, values, beliefs, individually-ascribed diversity, and differences arising through relationality in the group process. Examples include:

I will describe diversity in two ways. First is diversity in culture, religion, and that aspect of diversity. And the other is diversity of opinion and way of thinking, perception. This is also [a] very important aspect of diversity which we encounter day-to-day .... But diversity in culture means a lot to me because when we have a diverse group, it means that there is a whole lot of sharing and a whole lot of different values, different aspects of thinking about the same idea in a very different way, so it enriches a lot. (P5)

They each bring their own history .... I'm amazed at sometimes how we each bring our own histories. (P20)

Member diversity was also described as fluid and changing through relationality in groups. Through interactions, differences were described as creating potential negative experiences for members, a source of conflict. 'Diversity arises when there's disagreement in our group.' (P9)

Sometimes it arises when people sort of highlight or disclose that they feel very different and they don't feel understood but that they don't fit in, or match with the norm ... an invisible diversity. (P6)

Participation in a group influenced members' experiences of diversity by shifting the emphasis away from demographic differences. Accordingly, participant engagement in deeper relationships within group seems to decrease the emphasis on socially-ascribed differences, focusing more on diversity arising through the group process. 


\section{Challenges associated with diversity}

\section{Group member attrition}

Despite its promise in groups, diversity was perceived by some groupworkers as a barrier to inclusion within the group due to preexisting marginalization of members, as interviewees explained.

I don't know if the diversity is the reason for someone keeping themselves outside of the group or it's maybe their previous experiences of being outside the margins ... an outsider doesn't want to be joined with the group as opposed to the group preventing somebody joining the group. (P19)

The aim to achieve homogeneity in group composition influenced some groupworkers' negative perceptions of diversity in groups. Member selection became a method to minimize diversity, based on the belief that increased diversity decreases group member experiences of universality and cohesion.

Two participants described the challenges in balancing a common group purpose with heterogeneity based on diversity.

A sense of commonality is so important and hugely therapeutic whether you are in just a support group or a therapy group. I think groups like to be homogeneous, it feels more comfortable for them, and that is unfortunate because a lot of the time, the more comfortable you are, the less work you are actually getting done. (P21)

But then I also believe that you want to be careful not to have too much diversity in a group because then it's hell on the facilitator to try and constantly bring it back to the commonalities if there are very few commonalities and the experiences are too diverse. (P7)

Some groupworkers experienced member diversity in groups as a factor leading to attrition.

There was definite racism going on, but they weren't openly acknowledging [it] in the group. But that was creating a tension in the group. And so ... when I brought it up, no one wanted to talk about it at that point obviously. Everyone was really uncomfortable. (P15)

We struggled to keep those [diverse members] in the group. Often we find that they drop out after a few sessions. (P12) 
As noted above, the groupworker may experience greater comfort when the group composition is similar and may project this desire onto group members.

Some groupworkers found that mainstream group methods and models were sometimes unresponsive to the needs of diverse populations. In some cases, differences were not recognized as contextually relevant, leading to various issues within group, including the attrition of group members. For example, a groupworker described a lack of diversity in the structure of a group's process relative to Indigenous ways of being, potentially negatively impacting group members.

First Nations Peoples have a different process. They have a different ideology, and depending on their world experience, the western ways are very damaging and hurtful and aren't trustworthy. (P17)

For group members who have historically experienced marginalization and oppression, traditional western approaches to diversity may not only be ineffective but damaging to group members.

\section{Varying the group process}

Participants recognized diversity in groups as a relational construct in the 'here and now' of group processes. Two positions around this relational construct were identified. For several groupworkers diversity was experienced as problematic.

There have been times where the person who feels outside won't respond well to being invited in by the group and will use their diversity as a reason to stay outside the group, for example, 'like you can't possibly understand what I'm experiencing right now.' (P10)

These conversations come up, and I think it influences the group in terms of who comes into our group. Who stays in our group, and who does not? (P22)

Conflict was often used interchangeably with diversity, as groupworkers did not recognize or understand how to respond to power dynamics that emerged around diversity.

[The] concern is that when it's around an issue of diversity that there's an 'us versus them' that can happen that I'm never very comfortable with. (P17) 
Participants who reported identifying conflict around differences also experienced struggles responding to power imbalances.

Often there's this elephant in the room, and I get paralyzed around that, and then I have this full steam ahead. We're going to ignore all that and just do what we're supposed to do. And it doesn't ever go well. (P5)

Alternatively, diversity was described as beneficial to the group process.

They are now becoming [closer] to each other and understanding each other's backgrounds and becoming more aware of their backgrounds, how people were raised in different cultures and their cultural traditions and all that stuff, and more respectful to each other. (P23)

These groupworkers accepted that differences could create conflict between individual members, between members and the group-as-awhole, or between members and the groupworker, yet be constructive. They perceived diversity as another source of conflict but still part of the group dynamics.

There's healthy conflict there in terms of it helps people challenge people to broaden their understanding of the world and therefore broaden their sense of empathy. (P21)

Participants described responding to the conflicts by acknowledging differences, role modelling responding to conflict, challenging unproductive perceptions, or denying diversity. For some groupworkers, diversity in social contexts became a stepping stone for building dialogue and cohesion. 'So, the larger social messaging about gender [is] often also the unifying experiences that help the group' (P17).

Notwithstanding this dichotomous difference in groupworker response to in-group diversity, all participants in this study reported that when conflicts occurred outside of the group, which played out in group, the dynamics generated a sense of helplessness. Groupworkers reported struggling to find options for responding to the macro conflict being played out in the microcosm of the group, as reflected below.

When the group is a microcosm and the conflict coming up in the group is a microcosm of what's happening outside of the community, how do you handle it? (P5) 
The groupworkers' self-efficacy in responding to diversity was related to pre-existing perceptions of diversity in groups.

The following examples explore groupworker understanding of how socially-ascribed approaches to diversity influenced group processes, such as cohesion.

Prejudice against disability would be more an issue [to group unity]. (P15)

As a society, we tend to think that one way is right... a better or worse, a right or wrong - that separates us from people. And what we want is connection. (P10)

As a relational construct, group facilitators perceived diversity as an interplay between interpersonal influences.

\section{Organizational influences}

Diverse populations were perceived as requiring resources beyond the typically offered services, creating demands on existing group programming, perceived as difficult to accommodate.

So, the whole question around diversity is looking at where we are putting our resources, but I think it's a very political issue. To accommodate diversity takes time and, therefore money. It just doesn't happen. (P16)

Some participants in this study described restrictive organizational policies reducing perceived or actual capacity to respond to diversity.

There are times when some of my colleagues felt threatened by other colleagues because we were making these changes to make it inclusive for everyone to be a part. (P19)

The organization's own policies [are] not very anti-oppressive, and it's very hard... so you're kind of always like fighting uphill battles or swimming upstream. (P11)

Diversity was viewed as an ongoing and unfolding challenge at the organizational level.

We really need more work to be done around areas of diversity. I think we need to continue to build partnerships ... to have conversations ... to offer best practices but also how can we learn from each other. (P20)

Safety to address conflict or concerns arising around diversity added a 
layer of complexity in understanding diversity in groupwork.

You have to have the courage to have very difficult conversations. You also have to have the room and the permission to do that work. Politically it's very dangerous. Because you can then be labelled and professionally you can be destroyed. (P17)

Conversely, inclusive practice at the organizational level supported groupworkers' willingness to recognize and celebrate diversity.

You have to feel safe at your work environment to be able to do safety work with clients .... We have now developed a social committee where we are trying to invite colleagues to share ... their backgrounds so we can learn about it not only as colleagues but then we can share this with our clients. (P19)

Participants' discussion of how the organization and its support of diversity highlighted how macro influences impact all phases of the group process.

\section{Discussion}

As shown in this study, Rosen, McCall and Goodkind (2017) noted groupworkers often feel overwhelmed and, in some cases, 'paralyzed' by the complexity of diversity present in groups (Singleton and Hays, 2008). Groupworkers may reduce personal discomfort by ignoring the 'elephant in the room' and deferring to easier or less tenuous aims such as more rigidly following a plan. This uncertainty about how to proceed can result in repeated challenges of power dynamics in the group by group members (Boler, 2017; Spencer, 2017). Also troubling are indications of group strategies to reduce the diversity in the group, thereby heightening commonalities, cohesion and comfort at the expense of respect for diversity (Rose and Chang, 2010; Shulman, 2009). Notably, accentuating commonality does not appear linked to less attrition among diverse members, suggesting that reducing diversity does not reduce participant attrition (Shulman, 2006; Toseland and Rivas, 2012). Rather, the findings here indicate that attention to diversity in the group renders it potentially more relevant and salient to the group diversity, including with groups involving Indigenous peoples (Guy, 2020).

In response, levels and complexity of diversity increase as self- 
reflection by groupworkers deepens (Rosen, McCall and Goodkind, 2017). Despite initial consideration of diversity focusing on individual members' characteristics, with deeper reflection, groupworkers view diversity as more nuanced and consisting of multiple facets that are both overt, meaning visible aspects of group member identity, and covert or more subtle, yet important distinctions among group members in ways of thinking or being (Olcoń, Gilbert and Pulliam, 2020). A parallel process can unfold in groups whereby visible differences among group members are initially focal points, but over time, other less visible facets of diversity are noted by group members. As groupworkers focus on outward characteristics of difference, such as race or gender, they demonstrate a limited understanding of conceptual, historical, and sociological knowledge about the multiple factors that contribute to our complex identities (Varghese, 2016).

\section{Diversity as a relational process}

Existing literature supports diversity as a process (Patrick and Kumar, 2012), as noted in this analysis. From social work and groupwork perspectives, it is hoped that group participants are accepted in their uniqueness, with interpersonal processes being central to the process (Rosenberger, 2014). However, until recently, there has been a limited focus in the group literature on the concept of diversity as central, and a similar neglect of how diversity may impact group process. As noted by Azzopardi and McNeill (2016), social workers will always be working with differences given the unique perspectives and experiences that each individual brings, even if they share some commonalities. These findings amplify the breadth and depth of diversity in situ, and as such, the importance of groupworkers recognizing and proactively attending to the fluidity of group diversities (Marsiglia et al, 2021), especially as various aspects of diversity are reported to both moderate and mediate the group's functioning (Fernandes and Polzer, 2015).

A key construct emerging in this exploration and celebration in groups was the notion of 'relationality' and the importance of relationship-based practice. In defining central characteristics of this practice, Wilson, Ruch, Lymbery and Cooper (2011, pp.7-8) suggest the professional relationship to be 'the medium through which the practitioner can engage with and intervene in the complexity of an 
individual's internal and external worlds.' Pelech and colleagues (2016, p. 28) recognize diversity as relational by contending that,

when people meet, diversity will always be present in their relationships. With this in mind, the task of working with diversity shifts from how to work with those who are perceived to be diverse to how to promote productive relationships between group members. Diversity, thus, becomes a state that exists in the relationships between group members that is always mediated by power and status.

Extending the concept of relational expressions of diversity, Marsiglia, Kulis and Lechuga-Peña (2021) state that conceptualizations of diversity are not fixed, but the relevance of social categories may change over time. This recognition of the salient presence of diversity arising 'in relationship' is consistent with our study findings.

Groupworkers may be positionally poised to address diversities (a) if indeed they feel structurally or organizationally enabled to do so (or not inhibited from doing so), (b) if they recognize the presence and layers of diversities, and (c) if they feel confident in using relevant skills to address potential or emergent conflict associated with such diversity (McNeill and Nicholas, 2019). This finding is consistent with Brown and Mistry (2006) results showing participants encountered skill deficits in responding to diversity in groups. Toward this end, integration of social group activities and values-centred practice may provide practice-based resources in group (Sulman et al, 2012), while acknowledging the influences external to the group. Van Veelen et al. (2013) note that a process focused on members' personal selves rather than socially-ascribed diversity may lead to members feeling an increased sense of belonging in the group while remaining different.

Groupworkers recognize that the group, as a microcosm of its social environment, is influenced by organizational and external social conditions (Nadan and Ben-Ari, 2013). Yet, groupworkers also bring personal agency within the confines of these imposed parameters. Paralleling the perceived challenges in addressing such diversity, groupworkers need 'courage to have very difficult conversations' to improve organizational responses (Singleton and Hays, 2008). Continued reflexivity and exploring power in the group, including selfreflection, emerge as critical to practice (Azzopardi et al , 2020, p.287), as does a 'continuous, mindful awareness of culture and diversity, 
including the complex ways in which they construct meaning and experience, [which] promotes effective and ethical practice.'

\section{Considering an intersectional approach to diversity in groupwork}

However, the definition of diversity that we produced does not fully address the complexity associated with individuals. For example, diversity may be explained with the presentation of an array of attributes and perspectives (Van Veelen et al, 2013). Each member's worldview brings meaning to experiences in group and informs ways of relating to others (Anderson, 1997; Van Veelen et al, 2013). We contend that it is extremely important that group facilitators and members understand the relationship or interactions of these various characteristics. A term commonly used to discuss the interplay of these attributes is 'intersectionality.' This term came to prominence in the late 1980s through the work of the noted legal scholar Kimberlé Crenshaw (Crenshaw, 1989; Mullings et al, 2021). She maintained that the term described how race, class, gender, and other individual characteristics intersect with one another and overlap. Canadian scholars Hankivsky and Cormier (2011, p.217) stress that intersectionality involves 'taking into account that social identities such as race, class, gender, ability, geography, and age interact to form unique meanings and complex experiences within and between groups in society. Within the context of groups, intersectionality is a useful way in understanding the ways in which race, class, and gender, as well as other characteristics, interact to create power differentials within social work groups. Intersectional approaches to diversity in groupwork will be further explored in upcoming articles.

\section{Study limitations}

Interviews continued to the point of data saturation but included a limited range of group types, with study participants primarily working with closed groups with a fixed number of weeks. Testing the upcoming model on open groups, such as drop-in groups, would help implement strategies for working with diverse populations when group dynamics shift frequently. Additionally, gathering qualitative data on the community-level impacts on the group, such as 
organizational policies, organizational climate for supporting diversity, and community climate between various groups is recommended. Determining such impacts would shed light on how broader external factors influence diversity in groups.

\section{Conclusions and future directions}

This paper has offered critical reflection on the literature and emerging findings relating to diversity in group practice. We have described the first two phases of our research project, involving interviews and focus groups with groupworkers. The complexity inherent in diversity in groups presented a challenge to participating groupworkers. Our findings revealed a much more complex understanding of diversity than commonly presented in the literature and group work education with a relational and intersectional focus. Although strategies that avoid or discount diversity may reduce discomfort, they also seemingly render groups at risk of suboptimal process and impact. Accordingly, this work celebrates diversity as central to groups, and in so doing, encourages groupworkers to attend to its presence.

In keeping with the traditional aims of groupwork, attending to diversity goes beyond the group to include assessing responses in the organizational and community contexts. Dialogue and change in responses to diversity in the areas of organizational climate, allocation of resources, as well as agency policy and procedures may be needed. Further, groupworkers must become aware of the dynamics of community-level diversity and prepare to foster diversity in their groups. Organizational support will be central to this effort.

Further development is needed in offering groupworkers and members tools to attend to and navigate diversity in situ, yet an important first step is recognizing its presence and importance. The need for greater reflexivity by workers seems to be central to making sense of less obvious aspects of diversity, such as values, personality, sexual orientation, life experience, and differing views. The formulation of critical strategies for advancing diversity in groupwork is crucial and will be presented in subsequent phases of our research. 


\section{References}

Alvarez, A.R. and Cabbil, L.M. (2002) The MELD program: promoting personal change and social justice through a year-long multicultural group experience. Social Work with Groups, 24, 1, 3-20

Ancona, D.G. and Caldwell, D.F. (1992) Demography and design: predictors of new product team performance. Organization Science, 3, 3, 321-341

Anderson, J. (1997) Social work with groups: a process model. University of Michigan: Prentice Hall

Apfelbaum, E. P., Stephens, N. M. and Reagans, R. E. (2016) Beyond one-sizefits-all: tailoring diversity approaches to the representation of social groups. Journal of Personality and Social Psychology, 111, 4, 547-566

Ayres, L. (2008) 'Semi-structured interview' in L. Given (Ed.) The Sage encyclopedia of qualitative research methods. California: Sage Publications

Azzopardi, C. (2020) Cross-cultural social work: a critical approach to teaching and learning to work effectively across intersectional identities. The British Journal of Social Work, 50, 2, 464-482

Azzopardi, C. and McNeill, T. (2016) From cultural competence to cultural consciousness: transitioning to a critical approach to working across differences in social work. Journal of Ethnic \& Cultural Diversity in Social Work, 25, 4, 282-299

Balgopal, P.R. and Vassil, T.V. (1983) Groups in social work: an ecological perspective. New York: Macmillan

Bemak, F. and Chung, R.C.Y. (2004) Teaching multicultural group counseling: perspectives for a new era. The Journal for Specialists in Group Work, 29, 1, 31-41

Boler, M. (2017) Pedagogies of discomfort: inviting emotions and affect in educational change in (dis)comfort zones: negotiating tensions and cultivating belonging in diverse college classrooms in Quebec. conference proceedings, pp.9-14

Brown, A. and Mistry, T. (2006) Group work with 'mixed membership' groups: issues of race and gender. Social Work with Groups, 28, 3-4, 133-148

Burnes, T.R. and Ross, K.L. (2010) Applying social justice to oppression and marginalization in group process: interventions and strategies for group counselors. The Journal for Specialists in Group Work, 35, 2, 169-176

Camacho, S. F. (2002) Addressing conflict rooted in diversity: the role of the facilitator. Social Work with Groups, 24, 3-4, 135-152

Chatman, J.A. and Flynn, F.J. (2001) The influence of demographic heterogeneity on the emergence and consequences of cooperative norms in 
work teams. Academy of Management Journal, 44, 5, 956-974

Claeys, G. (2000) The' survival of the fittest' and the origins of social Darwinism. Journal of the History of Ideas, 61, 2, 223-240

Corbin, J. and Strauss, A. (2014) Basics of qualitative research: techniques and procedures for developing grounded theory. California: Sage Publications

Coyle, G. (1930) Social processes in organized groups. New York: Richard R. Smith Crenshaw, K. (1989) Demarginalizing the intersection of race and sex: a Black Feminist critique of antidiscrimination doctrine, feminist theory, and antiracist politics. University of Chicago Legal Forum, 1989, 1/8, 139-167

Doyle, R. and George, U. (2008) Achieving and measuring diversity: an organizational change approach. Social Work Education, 27, 1, 97-110

Fernandes, C. R. and Polzer, J. T. (2015) Diversity in groups. Emerging trends in the social and behavioral sciences: an interdisciplinary, searchable, and linkable resource. Hoboken: John Wiley \& Sons (pp.1-14)

Flores, P. J. (2017) Attachment theory and group psychotherapy. International Journal of Group Psychotherapy, 67, S50-S59

Galinsky, A. D., Todd A. R., Homan, A. C., Phillips, K. W., Apfelbaum, E. P., Sasaki, S. J., Richeson, A. J., Olayon, J. B., and Maddux, W. W. (2015) Maximizing the gains and minimizing the pains of diversity: a policy perspective. Perspectives on Psychological Science, 10, 6, 742-748

Ganzer, C. and Ornstein, E. D. (2002 ) A sea of trouble: a relational approach to the culturally sensitive treatment of a severely disturbed client. Clinical Social Work Journal, 30, 127-144

Glaser, B. and Strauss, A. (1967) The discovery of grounded theory: strategies for qualitative research. Chicago: Aldine De Gruyter

Goroff, N. (1980) Social group work: an intersystemic frame of reference' in A. Alissi (Ed.,) Perspectives on social group work practice. New York: The Free Press ( pp.292-303)

Green, Z. and Stiers, M. J. (2002) Multiculturalism and group therapy in the United States: a social constructivist perspective. Group, 26, 233, 233-246 Greene, B. (2004) African American lesbians and other culturally diverse people in psychodynamic psychotherapies: useful paradigms or oxymoron? Journal of Lesbian Studies, 8, 1/2, 57-77

Guy, D. (2020) Paddling to enlightenment: an indigenous group work experience. Social Work with Groups, 43, 1-2, 8-13

Hankivsky, O. and Cormier, R. (2011) Intersectionality and public policy: some lessons from existing models. Political Research Quarterly, 64, 1, 217-229

Harrison, D. A., Price, K. H. and Bell, M. P. (1998) Beyond relational demography: time and effects of surface- and deep-level diversity on work 
group cohesion. Academy of Management Journal, 41, 1, 96-107

Hiranandani, V. (2012) Diversity management in the Canadian workplace: towards an anti-racism approach. Urban Studies Research, https://doi. org/10.1155/2012/385806

Hitt, M., Miller, C. and Colella, A. C. (2015) Organizational behavior. Hoboken: Wiley

Inegbedion, H., Sunday, E. and Asaleye, A. (2020) Managing diversity for organizational efficiency. Sage Open. https://doi. org/10.1177/2158244019900173

Jordaan, M. and Jordaan, D. (2019) Diversity in groups-students' reflection, paper presented at the 8th Research in engineering education symposium, REES 2019, Cape Town

Kaiser, C. (1958) The social group work process. Social Work with Groups, 3, 2, 67-75

Lincoln, Y. S. and Guba E. G. (1985) Naturalistic inquiry. Newbury Park: Sage Publications

Low, J. (2013) Unstructured and semi-structured interviews in health research. in M. Saks \& J. Allsop (Eds.) Researching health: Qualitative, quantitative and mixed methods. (2nd ed.) London: Sage (pp.87-105)

Marbley, A. F. (2004) His eye is on the sparrow: a counselor of color's perception of facilitating groups with predominantly White members. The Journal for Specialists in Group Work, 29, 3, 247-258

Marsiglia, F. F., Kulis, S. S. and Lechuga-Peña, S. (2021) Diversity, oppression, E change: culturally grounded social work. Oxford: Oxford University Press

McIntosh, M. J. and Morse, J. M. (2015) Situating and constructing diversity in semi-structured interviews. Global Qualitative Nursing Research, 2, 2333393615597674

McLeod, P., Lobel, S. and Cox, T. (1996)Ethnic diversity and creativity in small groups. Small Group Research, 27, 2, 248-264

McNeill, T. and Nicholas, D. B. (2019) Creating and applying knowledge for critical social work practice: reflections on epistemology, research, and evidence-based practice. Journal of Ethnic \& Cultural Diversity in Social Work, 28, 4, 351-369

Miller, J., Donner, S. and Fraser, E. (2004) Talking when talking is tough: taking on conversations about race, sexual orientation, gender, class and other aspects of social identity. Smith College Studies in Social Work, 74, 2, 377-392 Mullings, D., Clarke, J., Thomas Bernard, W., Este, D. and Giwa, S. (2021) Africentric social work. Manitoba: Fernwood Press

Nadan, Y. and Ben-Ari, A. (2013) What can we learn from rethinking 
'multiculturalism' in social work education? Social Work Education, 32, 8, 1089-1102

Newcomer, K. E., Hatry, H. P. and Wholey, J. S. (2015) Conducting semistructured interviews. Handbook of Practical Program Evaluation. Hoboken: Wiley Publications (p.492)

Newstetter, W., Feldstein, M. and Newcomb, M. (1938) Group adjustment: a study in experimental sociology. Cleveland: School of Applied Sciences, Western Reserve University

Northen, H. (1988) Social work with groups. 3rd ed. New York: Columbia University Press

Olcoń, K., Gilbert, D. J. and Pulliam, R. M. (2020) Teaching about racial and ethnic diversity in social work education: a systematic review. Journal of Social Work Education, 56, 2, 215-237

O'Reilly, C., Caldwell, D. and Barnett, W. (1989) Work group demography, social integration and turnover. Administrative Science Quarterly, 34, 21-37

Padgett, D. K.(2008) Qualitative methods in social work research. 2nd ed. California: Sage Publications

Patrick, H. A. and Kumar, R. J. (2012) Managing workplace diversity: issues and challenges, Sage Open, 2. https://doi.org/10.1177/2158244012444615

Patton, M. Q. (2002) Qualitative research \& evaluation methods. 3rd ed. California: Sage Publications

Pelech, W., Basso, R., Lee, C. and Gandarilla, M. (2016) Inclusive group work. Chicago: Lyceum Books

Pelled, L. H., Eisenhardt, K. M. and Xin, K. R. (1998) Exploring the black box: an analysis of work group diversity, conflict, and performance. Administrative Science Quarterly, 44, 1,1-28

Phillips, L.T., Slepian, M.L. and Hughes, B.L. (2018) Perceiving groups: the people perception of diversity and hierarchy. Journal of Personality and Social Psychology, 114, 5, 766

Phillips, H. (1957) Essentials of social group work skill. New York: Association Press

Rittner, B., Nakanishi, M., Nackerud, L. and Hammons, K. (1999) How MSW graduates apply what they have learned about diversity to their work with small groups. Social Work with Groups, 35, 3, $421-431$

Rose, S. and Chang, H. (2010) Motivating clients in treatment groups. Social Work with Groups, 33, 260-277

Rosen, D., McCall, J. and Goodkind, S. (2017) Teaching critical self-reflection through the lens of cultural humility: an assignment in social work diversity course. Social Work Education, 36, 289-298 
Rosenberger, J. (2014) Relational social work practice with diverse populations. New York: Springer Press

Roysircar, G. (2008) A response to 'Social privilege, social justice, and group counseling: an inquiry': Social privilege: counselors' competence with systemically determined inequalities. Journal for Specialists in Group Work, $33,4,377-384$

Saino, M. (2003) A new language for groups: multilingual and multiethnic group work. Social Work with Groups, 26, 1, 69-82

Shapiro, B. Z. (1990) The social work group as social microcosm: 'frames of reference' revisited. Social Work with Groups, 13, 2, 5-21

Shaw, J. B. and Barrett-Power, E. (1998) The effects of diversity on small work group processes and performance. Human Relations, 51, 10, 1307-1325

Shulman, L. (2009) Preliminary Phase. in A. Gitterman \& G. Salmon (Eds.) Encyclopedia of Social Work with Groups. New York: Routledge ( pp. 109-111) Shulman, L. (2006) The skills of helping individuals, families, groups, and communities. 5th ed. California: Milton, Thomson-Brooks/Cole

Singleton, G. E. and Hays, C. (2008) Beginning courageous conversations about race. in M. Pollock (Ed.) Everyday antiracism: getting real about race in school. New York: The New Press (pp.18-23)

Smith, L. C. and Shin, R. G. (2008) Social privilege, social justice and group counselling: an inquiry. Journal for Specialists in Group Work, 33, 4, 351-366 Spencer, M.S. (2017) Microaggressions and social work practice, education, and research. Journal of Ethnic \& Cultural Diversity in Social Work, 1-2, 1-5

Sullivan, N. (2004) Conflict as an expression of difference: a desirable group dynamic in anti-oppressive social work practice. in C. Carson et al. (Eds.) Growth and Development Through Group Work. Binghampton, NY: Haworth Press (pp.75-89)

Sulman, J., Kanee, M., Day, C., Stewart, P. and Savage, D. (2012)Exploring exclusion. Groupwork, 22,1, 7-26

Thomas, D. (2006) A general inductive approach for analyzing qualitative evaluation data. American Journal of Evaluation, 27, 2, 237-246

Toseland, R. W. and Rivas, R. F. (2012) An introduction to group work practice. Boston: Pearson Education

Tropp, E. (1969) A humanistic foundation for group work practice. New York: Selected Academic Readings

Tuckett, A. G. (2005) Part II: Rigor in qualitative research: complexities and solutions. Nurse Researcher, 13, 1, 29-42

Van Knippenberg, D. and Schippers, M. C. (2007) Work group diversity. The Annual Review of Psychology, 58, 515-541 
Van Veelen, R., Otten, S. and Hansen, N. (2013) A personal touch to diversity: self-anchoring increases minority members' identification in a diverse group. Group Processes \& Intergroup Relations, 16, 6, 671-683

Varghese, R. (2016) Teaching to transform? Addressing race and racism in the teaching of clinical social work practice. Journal of Social Work Education, 52, supl, S134-S147

Weber, T.J., Sadri, G. and Gentry, W.A. (2018) Examining diversity beliefs and leader performance across cultures. Cross Cultural \& Strategic Management, $25,3,382-400$

Wierzbicki, M. and Pekarik, G. (1993) A meta-analysis of psychotherapy dropout. Professional Psychology, 24, 190-195

Wilson, K., Ruch, G., Lymbery, M. and Cooper, A. (Eds.) (2011) Social work: An introduction to contemporary practice. (2nd ed.) Harlow: Pearson Education

Yadav, S. and Lenka, U. (2020) Diversity management: a systematic review. Equality Diversity and Inclusion: An International Journal, 39, 8, 901-929

Zenger, T. and Lawrence, B. (1989) Organizational demography: the differential effects of age and tenure distributions on technical communications. Academy of Management Journal, 32, 353-376 